\title{
Production and characterization of natural lemonade powder using $\beta$-Cyclodextrin particles
}

\section{Yasemin İncegül' $^{1}$, Mustafa Karaboyacı ${ }^{2}$ Ebru Aydın ${ }^{1}$, Muhammed Mustafa Özçelik ${ }^{1}$, Gülcan Özkan ${ }^{1 *}$}

\begin{abstract}
Encapsulation of lipophilic food ingredients with cyclodextrin improves the stability of aromas, vitamins and coloring matter, as well as the prolongation of the product shelf life by preserving the product both physically and chemically. In this study, we aim to produce natural lemonade powder contains lemon peel oil, lemon juice, riboflavin, citric acid and stevia with B-cyclodextrin. Total moisture content, total oil content, $\mathrm{pH}$, titration acidity, and color of the encapsulated lemonade were analysed. As well as total phenolic content, free radical scavenging activity, antidiabetic activity, volatile profile and sensory properties were determined. As a result, total moisture content, total oil content as lemon oil, $\mathrm{pH}$, titration acidity, and color $\left(\mathrm{L}^{*}, \mathrm{a}^{*}, \mathrm{~b}^{*}\right)$ of the encapsulated lemonade were $7.14 \%, 8.3 \%, 3.79,0.48 \mathrm{mg}$ citric acid/g, and $56.6\left(\mathrm{~L}^{*}\right),-4.38\left(\mathrm{a}^{*}\right), 10.93\left(\mathrm{~b}^{*}\right)$. While total phenolic content and major volatile compound (limonene) of encapsulated lemonade sample were $5.69 \mathrm{GAE} / \mathrm{g}$ and $59.58 \%$, the activity of antidiabetic and free radical scavenging as antioxidant were not found. In assessing sensory characteristics, a hedonic scale was used in the range of 1 to 9 , and that the samples are liked by taking points around 7 . In our study, it is predicted that the antidiabetic and antioxidant activity of encapsulated lemonade could not be determined because encapsules could be produced only by using a little amount of lemon oil and lemon juice.
\end{abstract}

Keywords: $\beta$-Cyclodextrin Encapsulation, Lemonade, Antioxidant, Antidiabetic, Volatile, Sensory

\section{Introduction}

In recent years, consumers prefer natural ready mix of food that provide various health benefits due to including functional bioactive components. Lemonade is one of them and traditionally a homemade drink using lemon juice and peel, water, and a sweetener such as cane sugar or honey. Citrus fruits such as lemon are used lemonade production and has been used in food, medicine and perfumery industry for centuries due to a unique nutritional value (Bruno et al., 2014). Especially Citrus peels are the waste product of fruit processing industry rich in essential oil (EO) and the oil contains limonene and linalool major volatile components (Min-Hsiung et al., 2009). The EOs has been widely used as preservatives in pharmaceuticals, foods and other industries, and are generally regarded as safe (GRAS) (Kıdem and Garba, 2017).

As pharmaceutically, the lemon peel also has high antioxidant, anticarsinogen and antimicrobial properties, and a diabetes lowering effect due to its high polyphenol content, which promotes stimulation or regeneration of $\beta$-cells (Naim et al., 2012; Kidem and Garba, 2017). Lemon peel extract was studied on mice with diabetes and significantly reduced blood glucose levels (Naim et al., 2012).

${ }^{1}$ Suleyman Demirel University, Faculty of Engineering, Department of Food Engineering, Isparta, TURKEY

${ }^{2}$ Suleyman Demirel University, Faculty of Engineering, Department of Chemical Engineering, Isparta, TURKEY

*Coreesponding author: gulcanozkan@sdu.edu.tr
Citation (Atıf): İncegül, Y., Karaboyacı, M., Aydın, E.,Özçelik M. M., Özkan, G. (2018). Production and Characterization of Natural Lemonade Powder Using $\beta$-Cyclodextrin particles Bilge International Journal of Science and Technology Research, 10-18. 
In food industry, lemon EOs is used as a flavoring agent in food products such as confectionery, bakery products, desserts, ice creams and soft drinks due to its volatile components having a characteristic aroma profile (González-Molina et al., 2010; Mei et al., 2009; Reineccius et al., 2005). Lemon oil also is used for providing a non-sour citrus aroma in lemon peel beverage such as lemonade and food formulations (Cannon et al., 2015).

It has been recently dwelled on the different encapculation methods and mixture of coating materials to produce powder of the beverages. Encapsulation is employed to protect chemically sensitive bioactive compounds from degradation due to adverse environmental conditions and is also used to control the release of the encapsulate and the different coating materials used for the encapsulation of bioactive compounds due to their long-term storage stability (Szente and Szejtli, 2004; Mourtzinos et al., 2008; Astray and Mejuto, 2009). Cyclodextrins $(\alpha, \beta$ and $\gamma$ ) are one of the best methods used in the encapsulation of many hydrophilic and hydrophobic molecules, flavor substances and the powder beverages production of fruits, vegetables and herbs in the food industry (Reineccius and Risch, 1986); (Reineccius et al., 2006; Avc1 and Dönmez, 2010) because of their shapes of three-dimensional and cylindrical. (Eastburn and Tao, 1994; Crini and Morcellet, 2002; Singh et al., 2002; Magnusdottir et al., 2002; Valle, 2004; Vermonden et al., 2009; Astray and Mejuto, 2009; Song et al., 2009).

In this study, it was aimed to produce natural lemonade powder. The mix of lipophilic food ingredients (lemon peel oil and riboflavin) and hyropylic ingredients (lemon juice, citric acid and stevia) encapsulated with $\beta$-cyclodextrin method to improve the stability of aromas, acidity and coloring matter, as well as to prolong of the product shelf life by preserving the product both physically and chemically.

\section{Material and Method}

\subsection{Material}

Materials used in this study are lemon juice, lemon peel oil, riboflavin, citric acid, stevia and beta cyclodextrin. Cold-pressed $100 \%$ lemon peel oil obtained from Botalife, $\beta$-cyclodextrin (Cavamax W7 pharma), and lemon juice were used as raw materials in the microencapsulation process. After encapsulation citric acid monohydrate (Sigma), riboflavin-5-phosphate sodium (DSM) and stevia powder (Takita) were added to the paste.

\subsection{Encapsulation Method}

Microencapsulation method is designed like Bhandari and colleagues' (1999) method. They use $70 \mathrm{ml}$ of distilled water for 100 grams of $\beta$-cyclodextrin. In this research, we used $9 \mathrm{~mL}$ of lemon juice for preparing 10 grams of $\beta$-cyclodextrin for to obtain more taste and flavor. If the liquid is used at a lower rate, the dough becomes solid too quickly and after that the additional components can not be dissolved in the dough solution. The ratio of $\beta$-cyclodextrin to lemon oil was 88:12 in dry basis like Bhandari and colleagues (1998). They found this ratio as an optimum amount (Bhandari et al., 1998). For preparing 10 grams of encapsulated lemon oil 8.8 grams of $\beta$-cyclodextrin dissolved in $9 \mathrm{~mL}$ of lemon juice and stirred in mechanical stirrer at 60 rpm. After dispersion of $\beta$-cyclodextrin than $1.2 \mathrm{~mL}$ of lemon oil added to mixture and stirred 15 minutes. Bhandari and colleagues (1999) found that 15 minutes is optimum kneading time for microencapsulation of lemon oil. After 15 minutes, $0.0125 \mathrm{~g}(12.5 \mathrm{ppm})$ of riboflavin-5-phosphate sodium added to the mixture. Followed by $1.2 \mathrm{~g}(6,000 \mathrm{ppm})$ citric acid and $6 \mathrm{~g}(30,000 \mathrm{ppm})$ stevia were added to dough mixture. The mixture was stirred until it becomes dense. The resulting dough mixture was dried at $70{ }^{\circ} \mathrm{C}$ for 24 hours in oven. Hardened dough is ground in the mortar and sieved from a 100-mesh sieve (Bhandari et al., 1999). And thus, instant lemonade powder is obtained.

\subsection{Total Moisture Content Analysis}

The total moisture contetn of lemon oil filled cyclodextrin powder complexes was determined by AOAC 925.45 method (AOAC, 1996). $2 \mathrm{~g}$ of samples was weighed into aluminum weighing container and dried in a 
at $70 \mathrm{C}$. After drying, the conteiner was covered and cooled to $25 \mathrm{C}$ in a desiccator with silica gel for about $20 \mathrm{~min}$ before weighing. This process was repeated every hour until the mass change was less than $2 \mathrm{mg}$.

\subsection{Total Oil Extraction Analysis}

For determination of total oil content of the cyclodextrin inclusion complexes, 2 grams of encapsulated cyclodextrin with constant weighing was boiled in hexane (powder hexane ratio is 1 to 20) for 30 minutes by using modified method of Bhandari et al. (1992) and Anandaraman and Reineccius (1987). After 30 minutes $100 \mathrm{~mL}$ destilled water was added to the solution and filtered. Filtrate was rinsed with hexane again and this process was repeated for 3 times. The last filtrate was analyses with GCMS to be sure about there are no oil in

the filtrate. Obtaioned residue was dried in an oven at $70{ }^{\circ} \mathrm{C}$ over a night. The amount of mass lost by the cyclodextrin was calculated as the oil ratio of the complex.

\subsection{Determination of $\mathrm{pH}$ value}

Lemonade $\mathrm{pH}$ values were determined using a $\mathrm{pH}$ meter (Hanna Instruments USA). The liquid product was read by directly immersing the probe.

\subsection{Determination of Titration Acidity}

$5 \mathrm{~g}$ of lemonade at room temperature is removed and titrated with $0.1 \mathrm{~N} \mathrm{NaOH}$ adjusted to $\mathrm{pH}$ 8.1. The result is expressed as citric acid.(Cemeroğlu, 2007)

\subsection{Color Analysis}

Lemonade color values are determined by automatic color device $(3 \mathrm{nh}, \mathrm{nh} 310) . \mathrm{L}^{*}, \mathrm{a}^{*}, \mathrm{~b}^{*}$ values were determined with the device.

\subsection{Total phenolic content}

Total phenolic content (TPC) of the extracts was determined according to the method of Li et al., (2006). Briefly, $0.4 \mathrm{~mL}$ of diluted extracts were mixed with $2 \mathrm{~mL}$ of 10 -fold diluted Folin-Ciocalteu's phenol reagent and $1.6 \mathrm{~mL}$ of $7.5 \% \mathrm{Na} 2 \mathrm{CO} 3$ was added. The mixture was allowed to stand for 1 hour. The absorbance versus prepared blank was read at $760 \mathrm{~nm}$. Six different concentrations of gallic acid solutions $(20-200$ $\mathrm{mg} / \mathrm{L}$ ) were used for calibrations. The final results were expressed as mg gallic acid equivalent (GAE) $\mathrm{g}$ of dry lemonade.

\subsection{Free radical scavenging activity}

Free radical scavenging activity as antioxidant properties is under the influence of holding free radicals and it's been determined by using 1, 1-diphenyl-2-picrilhidrazil (DPPH) method (Dorman et al., 2003). The powder of lemonade $(2 \mathrm{~g}$ ) was solved in $250 \mathrm{~mL}$ water. The solved lemonade in water were added $450 \mathrm{lL}$ of Tris-HCL solution $(50 \mathrm{mM}-\mathrm{pH} 7.4)$ and $1 \mathrm{ml} \mathrm{DPPH}(0.1 \mathrm{mM})$ and were incubated for 30 minutes. The absorbance of the standard and the samples were measured at $517 \mathrm{~nm}$. Before calculating $\mathrm{IC}_{50}$ value, antiradical activity $\%$ of the extracts at different doses was determined using the following formula:

Free radical scavenging activity $\%=100 \mathrm{x}$ (absorbance of the control - absorbance of the sample/absorbance of the control)

\subsection{Determination of antidiabetic activity}

The initial steps of method development involved determining the activities of sucrase, in an acetone-extract of rat intestinal tissues and improving a previously published method (Aydin, 2015) by analysing glucose production from sucrose with the hexokinase assay. 


\subsection{Volatile compounds analysis}

The $2 \mathrm{~g}$ lemonade sample is transferred to a $15 \mathrm{ml}$ volumetric vial that is sealed with a silicone septum. The sample is placed in a $45{ }^{\circ} \mathrm{C}$ heater block with stirring by means of a magnetic stirrer. Balancing was performed for 15 minutes and then, a Carboxen/polydimethylsiloxane manual SPME fibre (75 mm Fused Silica, Supelco Ltd., Bellefonte, PA, USA) was inserted into the vial and maintained in the head-space for 30 $\mathrm{min}$ at $45 \mathrm{C}$ to extract volatile compounds from the lemonade. Finally, the fiber was placed in the injection block of the gas chromatograph at $250{ }^{\circ} \mathrm{C}$ for 5 minutes to determine the flavor compounds obtained from lemonade (Cevik et al., 2016).

\subsection{Sensory analysis}

Sensory analysis was carried out at Süleyman Demirel University Faculty of Engineering Department of Food Engineering. A hedonic scale was used between 1 and 9. The number 1 on the scale is very bad, 5: the middle and 9 were expressed in perfect form.

\section{Results and Discussion}

\subsection{Physicochemical properties of encapsulated lemonade}

The moisture content of the $\beta$-cyclodextrin inclusion complex was calculated $7.14 \%$ by the vacuum-drying method (AOAC, 1990). Bhandari et al., (1999) used this method and the calculate moisture content of the $\beta$ cyclodextrin $9.94 \%$. Results are similar, and the moisture content of a sample is influenced by the climate of the studied area and the humidity in the air.

The resulting total oil extraction results can also be evaluated as inclusion efficiency. As a result of the analysis, it was determined that the cyclodextrin inclusion complex contains $8.3 \%$ lemon oil. Bhandari et al. (1998) used the same method and they reported that $94.51 \mathrm{mg}$ of volatiles/g of cyclodextrin, that is $9.451 \mathrm{~g}$ of oil volatiles (or $9.68 \mathrm{~g}$ of lemon oil) per $100 \mathrm{~g}$ of $\beta$-cyclodextrin. Our total oil content is smilar to this result. In our method we used hexane for to remove all lemon oil from hydrofobic cavity. Because hexan is an apolar solvent and apolar cavity wants to take this solvent inside. Out side of the cyclodextrin is polar so after boiling with hexane we add water to the flask for to solve cyclodextrin and than solution can be filter easly.

The lemonade $\mathrm{pH}$ and titration acidity values obtained by dissolving $2 \mathrm{~g}$ of lemonade preparation in $200 \mathrm{ml}$ water were found to be $3.79 \pm 0.01$ and $0.48 \pm 0.02 \mathrm{mg}$ citric acid/g sample respectively. Lemon by-product characteristics were investigated, and the $\mathrm{pH}$ value was found to be 3.80 . This value was found in the literature between 3.14-3.96 (M'hiri et al., 2018). Lemon peel oil is a by-product of lemon and is encapsulated in the production of lemonade and re-dissolved by dissolution in water. The $\mathrm{pH}$ value of lemonade produced by using lemon juice and lemon peel oil was found in the current range in the literature. It may be due to the presence of organic acids such as citric, ascorbic and malic acids in the lemon byproduct and lemonade high acidity.

Lemonade $\mathrm{L}^{*}, \mathrm{a}^{*}, \mathrm{~b}^{*}$ values were found to be $56.6 \pm 0.56,-4.38 \pm 0.16$ and $10.93 \pm 0.22$ respectively. When the color values of lemon wastes are examined, $\mathrm{L}^{*}, \mathrm{a} *$ and $\mathrm{b} *$ values are found as 43.78, 4.13 and 12.72 respectively (M'hiri et al., 2018). When we compare our results withthe study, the value of a* is very low, which can be explained by the greening of the resulting color of the lemonade enriched with riboflavin.

\subsection{Total phenolic compounds and functional properties of encapsulated lemonade}

As a result of total phenolic substance amount analysis performed, the phenolic content of lemonade was determined as $5.69 \pm 0.18 \mathrm{mg} \mathrm{GAE} / \mathrm{g}$. In the study conducted by M'hiri et al. (2018) the composition of lemon waste products was investigated, and the total amount of phenolic substance was found to be $55.2 \mathrm{mg}$ GAE / g. The waste consists of lemon peel, lemon seed, dough and water. In our work, only lemon oil and lemon juice are used. The phenolic content we found could be found to be lower because of the use of only lemon oil and water and because of the encapsulation process. 
Free radical scavenging and antibiabetic activities as functional properties of powder lemonade produced in the study have been reviewed. It is determined that, as a result of the analysis carried out, the antidiabetic and antioxidant properties of the lemonade are not important due to the lowest content of lemonade oil and phenolic in encapsulated product. Also, it was found that prepared lemonade did not inhibit the sucrase activity. Therefore, it could conclude that lemonade does not have any antidiabetic activity.

\subsection{Volatile properties of encapsulated lemonade}

The oil obtained from the colored parts of the citrus peels consists of more than 100 compounds. The results of analysis of the lemonade volatile compounds are given in the following Table 1. Composition of these oils was terpenecarbons, oxygenated compounds and non-volatile compounds. Some important compounds in citrus oils found as alpha-pinene, beta-pinene, myristine, lemonine, gamma-terpinene, valencene, sabinen, neral and geranial (Karhan, 2006). The main component was determined that as limonene in proportion to one of the most important components of essential oil (37.63-69.71\%) of sour lemon peel by Bourgou et al. (2012). In another study also conducted on lemon oil, it was stated that volatile oil predominates mainly of Limonen (61.64\%), $\beta$-pinene (13.85\%) and $\gamma$-terpinene (9.95\%) (Hasani et al., 2018). In our study, limonene, $\beta$-pinene and $\gamma$-terpinen and fractions encapsulated with $\beta$-cyclodextrin were determined as $59.58 \%$ and $12.29 \%$ and $4.39 \%$ respectively. When these ratios are examined it can be concluded that the essential components of lemon oil are successfully encapsulated with CD's. The main constituents encapsulated in the study were limonene $(59.58 \%), \gamma$-terpinene $(12.29 \%), \beta$-pinene $(4.39 \%), \beta$-pisabolene $(3.89 \%)$ and $\beta$ myrcene (2.59) \%.

Table 1. Lemonade volatile components

\begin{tabular}{llll}
\hline Name of volatile compounds & Area & Area\% \\
\cline { 1 - 1 }$\alpha$-Thujene & 193910 & 0.06 \\
C-Pinene & 3328894 & 1.00 \\
Sabinene & 532726 & 0.16 \\
$\beta$-Pinene & 340410 & 0.10 \\
$\beta$-Myrcene & 14591282 & 4.39 \\
l-Phellandrene & 8627343 & 2.59 \\
$\alpha$-Terpinene & 704094 & 0.21 \\
p-Cymene & 1765288 & 0.53 \\
Limonene & 6160958 & 1.85 \\
Z-Ocimene & 198119060 & 59.58 \\
$\beta-O c i m e n e$ & 492894 & 0.15 \\
$\gamma$-Terpinene & 1020180 & 0.31 \\
Isolimonen & 40880843 & 12.29 \\
$\alpha$-Terpinolene & 176928 & 0.05 \\
p, $\alpha$-Dimethylstyrene & 5277306 & 1.59 \\
Nonanal & 7506035 & 2.26 \\
E-Sabinene hydrate & 127328 & 0.04 \\
$\beta$-Fenchyl alcohol & 262164 & 0.08 \\
Decanal & 364244 & 0.11 \\
Z-Citral & 89169 & 0.03 \\
E-Citral & 1266660 & 0.38 \\
$\delta$-Elemene & 4044566 & 1.22 \\
Citronellyl acetate & 121603 & 0.04 \\
Neryl acetate & 84169 & 0.03 \\
Linalyl acetate & 5133534 & 1.54 \\
\hline
\end{tabular}




\begin{tabular}{lll}
\hline$\beta$-Elemene & 232858 & 0.07 \\
Caryophyllene & 1828104 & 0.55 \\
$\alpha$-Bergamotene & 6030590 & 1.81 \\
$($ E)- $\beta$-Farnesene & 640090 & 0.19 \\
$\beta$-Santalene & 210499 & 0.06 \\
$\beta$-Himachalene & 157143 & 0.05 \\
Curcumene & 137105 & 0.04 \\
Isocaryophyllene & 297755 & 0.09 \\
$\beta$-Selinene & 120377 & 0.04 \\
Valencene & 191172 & 0.06 \\
$\alpha-$ Selinene & 208172 & 0.06 \\
$\alpha$-Bisabolene & 1610211 & 0.48 \\
(E,E)- $\alpha$-Farnesene & 958931 & 0.29 \\
$\beta$-Bisabolene & 12941173 & 3.89 \\
$\alpha$-Cedren & 373112 & 0.11 \\
Cadinene & 173281 & 0.05 \\
$\alpha$-Patchoulene & 136253 & 0.04 \\
$\alpha$-Humulene & 365568 & 0.11 \\
\hline TOTAL & 332553794 & 100.00 \\
\hline
\end{tabular}

\subsection{Sensory properties of encapsulated lemonade}

The color, odor, flavor, sweetness, bitterness, sourness lemon flavor, taste of lemonade and overall appreciation were evaluated sensory using hedonic scale. It is expressed that the smell and aroma of the lemonade evaluated by the panelists is likes and resembles the classical lemonade. Likewise, it was determined that lemon flavor was enough and liked. These results show us that the encapsulation process using cyclodextrin particles is successful in lemonade odor, taste and aroma. Lemonade has parallel scores when assessed for bitterness and sourness originating from phenolics, and this value is around 7. So, the product is liked by bitter taste and sourness taste. The results obtained are given in Figure 1.

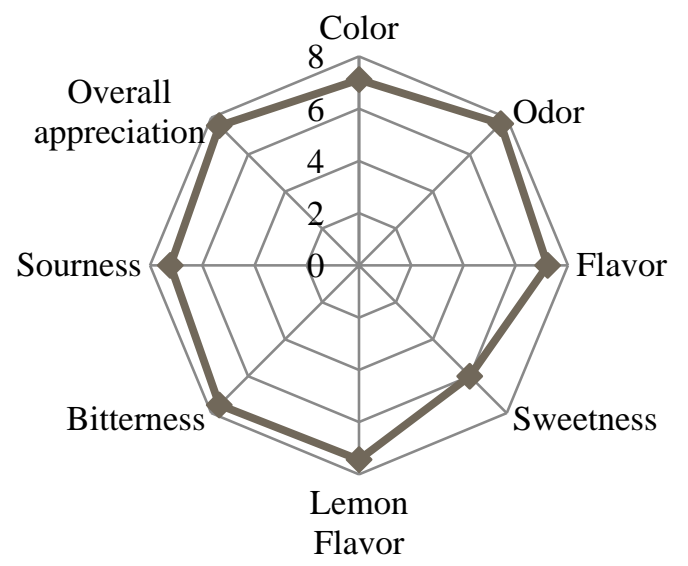

Figure 1. Sensory properties of lemonade

\section{Conclusions}

In summary, the mixure of lemon oil, lemon juice, citric acid, stevia and riboflavin was succesfully encapsulated by using beta cyclodextrin to produce the powder of natural lemonade. Also, the volatile 
subtances of lemon oil was encapsulated succesfully and the sensory properties of the last product were highly liked by the panelist. However, the functional properties as radical scavenging activity and antidiabetic activity of the powder of natural lemonade were not determined. As a result, the encapsulated lemonade product could be using home appliances and industry as natural powder formulation in practical.

\section{References}

Anandaraman, S., and Reineccius, G. (1987). Analysis of encapsulated orange peel oil. Perfumer and Flavorist 12, 33-39.

AOAC. (1990). In Official Methods of Analysis of the Association of Official Analytical Chemists, 5th ed.; Helrich, K., Ed.; AOAC International: Arlington, VA, p. 1010.

Astray, G., and Mejuto, J. C. (2009). A Review on The Use of Cyclodextrins in Foods, Food Hydrocolloids $23,1631-1640$.

Avc1, A., and Dönmez, S. (2010). Cylodextrins and Their Usage in The Food Industry. Gida Dergisi, 35, 305312.

Aydin, E., (2015).Effects of Natural Products on Sugar Metabolism and Digestive Enzymes (Doctoral dissertation, University of Leeds).

Bhandari, B. R., Dumoulin, E. D., Richard, H. M. J., Noleau, I., and Lebert, A.M. (1992). Flavour encapsulation by spray drying: Application to citral and linalyl acetate. J. Food Sci. 57, 217-221.

Bhandari, B. R., Arcy, B. R. D., Le, L., and Bich, T. (1998). Lemon Oil to $\beta$-Cyclodextrin Ratio Effect on the Inclusion Efficiency of $\beta$-Cyclodextrin and the Retention of Oil Volatiles in the Complex. J. Agric. Food Chem., 46, 1494-1499.

Bhandari, B. R., Arcy, B. R. D., and Padukka, I. (1999). Encapsulation of Lemon Oil by Paste Method Using $\beta$-Cyclodextrin: Encapsulation Efficiency and Profile of Oil Volatiles. J. Agric. Food Chem., 47, 5194-5197.

Bruno, L., Spadafora, N.D., Iaria, D., Chiappetta, A., Bitonti, M.B. (2014). Developmental stimuli and stress factors affect expression of ClGLP1: an emerging allergen-related gene in Citrus limon. Plant Physiol. Biochem. 79, 31-40.

Bourgou, S., Rahali, F. Z., Ourghemmi, I., and Sa, M. (2012). Changes of Peel Essential Oil Composition of Four Tunisian Citrus during Fruit Maturation. The cientific World Journal, 1-10.

Cannon, R.J., Kazimierski, A., Curto, N.L., Li, J., Trinnaman, L., Janczuk, A.J., Agyemang, D., Da Costa, N.C., Chen, M.Z., 2015. Identification, synthesis, and characterization of novel sulfur-containing volatile compounds from the in-depth analysis of Lisbon lemon peels (Citrus limon L. Burm f. cv. Lisbon). J. Agric. Food Chem. 63, 1915-1931.

Cemeroğlu, B. (2007). Gıda Analizleri (Gıda Tekno). Bizim Büro Basımevi, 535s, Ankara.

Cevik, S., Ozkan, G., and Mustafa, K. (2016). Optimization of malaxation process of virgin olive oil using desired and undesired volatile contents LWT 73.

Crini, G., and Morcellet, M. (2002). Synthesis and applications of adsorbents containing cyclodextrins. J. Sep. Sci., (25), 789-813.

Dorman, H. J. D., Koşar, M., Kahlos, K., Holm, Y., and Hiltunen, R. (2003). Antioxidant Properties and Composition of Aqueous Extracts from Mentha Species, Hybrids, Varieties, and Cultivars. Journal of Agricultural and Food Chemistry, 51(16), 4563-4569.

Eastburn, S., and Tao, B. (1994). Application of modifiyied cyclodextrins. Biotechnol Adv., 12, 325-339.

González-Molina, E., Domínguez-Perles, R., Moreno, D. A., and García-Viguera, C. (2010). Natural bioactive compounds of Citrus limon for food and health. Journal of pharmaceutical and biomedical analysis, 51(2), 327-345. 
Hasani, S., Mahdi, S., and Ghorbani, M. (2018). International Journal of Biological Macromolecules Nanoencapsulation of lemon essential oil in Chitosan-Hicap system. Part 1: Study on its physical and structural characteristics. International Journal of Biological Macromolecules, 115, 143-151.

Karhan, M. (2006). Turunçgil Kabuk Yağlarının Elde Edilmesi ve Gıda Endüstrisinde Kullanımı. Gıda Teknolojileri Elektronik Dergisi, 3, 71-77.

Kıdem, H.U., and Garba, U. (2017) Citrus peel essential oils: a review on composition and antimicrobial activities. International Journal of Food Safety, Nutrition, Public Health and Technology; Coimbatore, 9 (5), 38-44.

Kwak, S. H., Jung, C. S., Shim, Y. S., and Ahn, J. (2002). Removal of Cholesterol from Cheddar Cheese by $\beta$-Cyclodextrin. J. Agric. Food Chem., 50, 7293-7298.

Kwak, H. S., Kim, S. H., Kim, J. H., Choi, H. J., and Kang, J. (2004). Immobilized $\beta$-Cyclodextrin as a Simple and Recyclable Method for Cholesterol Removal in Milk. Arch Pham Res, 27(8), 873-877.

Li, Y., Guo, C., Yang, J., Wei, J., Xu, J., and Cheng, S. (2006). Evaluation of antioxidant properties of pomegranate peel extract in comparison with pomegranate pulp extract. Food Chemistry, 96, 254-260.

Magnusdottir, A., Mason, M., and Loftsson, T. (2002). Cyclodextrins. J Inclusion Phenom Macrocyclic Chem., 44, 213-218.

Mei, L., Choi, S. J., Alamed, J., Henson, L., Popplewell, M., McClements, D. J., et al. (2009). Citral stability in oil-in-water emulsions with solid or liquid octadecane. Journal of Agricultural and Food Chemistry, 58(1), 533-536.

M'hiri, N., Ghali, R., Nasr, I. Ben, and Boudhrioua, N. (2018). Effect of different drying processes on functional properties of industrial lemon byproduct. Process Safety and Environmental Protection, 116.

Min-Hsiung P. (2009). Chemopreventive effects of natural dietary compounds on cancer development. Second Symposium on FranceTaiwan Frontiers of Science Tentative Program.

Mourtzinos, I., Kalogeropoulos, N., Papadakis, S. E., Konstantinou, K., and Karathanos, V. T. (2008). Encapsulation of Nutraceutical Monoterpenes in $\beta$-Cyclodextrin and Modified Starch. Sensory and Food Quality, 73(1), 89-94.

Naim, M., Amjad, F. M., Sultana, S., Isalm, S. N., and Amjad, M. (2012). A Comparative Study of Antidiabetic Activity of Hexane-Extract of Lemon Peel (Limon citrus) and Glimepiride in AlloxanInduced Diabetic Rats. Bangladesh Pharmaceutical Journal, 15(2), 131-134.

Reineccius, G. A., and Risch, S. J. (1986). Encapsulation of artificial flavors by $\beta$-cyclodextrin. Perfumer and Flavorist, 11(4), 1-6.

Reineccius, T. A., Reineccius, G. A., Peppard, T. L. (2005). The effect of solvent interactions on $\alpha-, \beta-$, and $\lambda$-Cyclodextrin/Flavouring molecular inclusion complexes. Journal of Agricultural and Food Chemistry, 53(2), 388-392.

Reineccius, T. A., Reineccius, G. A., and Peppard, T. I. (2006). Flavor Release from Cyclodextrin Complexes: Comparison of Alpha, Beta, and Gamma Types. Journal of Food Science (68).

Reineccius, T., Reineccius, G., and Peppard, T. (2008). Utilization of $\beta$-Cyclodextrin for Improved Flavor Retention in Thermally Processed Foods. Journal of Food Science (69).

Singh, M., Sharma, R., and Banerjee, U. C. (2002). Biotechnological Aplications of Cyclodextrins. Biotechnol Advances, 20, 341-359.

Song, X. Le, Bai, L., Xu, M. X., He, J., and Pan, Z. S. (2009). Inclusion Complexation, Encapsulation Interaction and Inclusion Number in Cyclodextrin Chemistry, 253, 1276-1284.

C, J. (1998). Introduction and General Overview of Cyclodextrin Chemistry. Chem Rev., 98, 1743-1753.

Szente, L., and Szejtli, J. (2004). Trends in Food Science and Technology, 15, 137-142. 
Valle, E. M. M. Del. (2004). Cyclodextrins and their uses: a review. Process Biochemistry, 39, 1033-1046.

Vermonden, T., Nostrum, C. F. Van, Hennink, W. E., and van de Manakker, F. (2009). Cyclodextrin-Based Polymeric Materials: Synthesis, Properties and Pharmaceutical/Biomedical Applications. Biomacromolecules, 10(12), 3157-3175. 